\title{
EFFECT OF SOCIO-CULTURAL IMPLICATIONS OF CARING FOR CHILDREN WITH INTELLECTUAL DISABILITY ON THE WELL- BEING OF FAMILIES IN NAKURU MUNICIPALITY, NAKURU COUNTY, KENYA
}

\author{
Esther Njeri Njoroge ${ }^{1}$, Erick Kiprono Bor $^{2}$ and Beatrice Onsarigo ${ }^{3}$ \\ ${ }^{1,2,3}$ Department of Peace, Security and Social Studies, Egerton University, P.o Box 536 - 20115, Egerton- \\ Njoro, KENYA.
}

DOI: 10.46609/IJSSER.2020.v05i12.006 URL: https://doi.org/10.46609/IJSSER.2020.v05i12.006

\begin{abstract}
The study sought to explore the effect of socio-cultural implications of caring for children with ID on well-being of families in Nakuru municipality, Nakuru County Kenya. This study was guided by the family system theory. It adopted the descriptive research design where life experiences of families of children living with intellectual disabilities were assessed using semistructured interviews. A sample of 84 families was selected from the families of 503 students attending eight special schools for the mentally handicapped using a multi-stage sampling plan that combined proportionate cluster sampling and purposive sampling techniques. The resultant data was analysed using descriptive statistics, inferential statistics, the thematic content analysis technique. Results show that $42.9 \%$ of the families of children with intellectual disability in Nakuru Municipality have low state of well-being. Stigmatization by the extended family and disruption in family relationship were the socio-cultural factors that have a significant influence on family well-being. The study recommends that to improve the well-being of families of children with ID, policymakers at the Ministry of Health should develop and rollout nationwide sensitization campaign aimed at addressing negative misconception about intellectual disability in order to reduce stigmatization of families.
\end{abstract}

Keywords: Socio-cultural, intellectual disability, children, well-being, family, Nakuru, Kenya

\section{Introduction}

Estimates suggest that there are approximately one billion people living with a disability or born disabled. The prevalence of disability continues to increase as chronic diseases such as cancer and diabetes are increasing even in the developing world (Yokota, Berger, Nusselder, Robine, Tafforeau, Deboosere \& Oyen, 2015). Children and adolescents constitute 200 million of those 


\section{International Journal of Social Science and Economic Research}

ISSN: $2455-8834$

Volume:05, Issue:12 "December 2020"

with disabilities and about $80 \%$ of these live in the developing world (UN Department of Economic and Social Affairs, 2018). Intellectual disability (ID) is among the common form of disabilities around the globe. In the United States of America (U.S), prevalence of ID stood at $6.99 \%$ of the population of all children aged between 3-17 years (Zablotsky, Black \& Blumberg, 2017) while in India, the condition affects 10.5 per every 1000 people (Lakhan, Ekundayo, \& Shahbazi, 2015).

With the above statistics, it is perturbing that ID issues have received so little attention in development efforts (Albert, 2004) especially where children are concerned. In fact, many aid organizations still do not have an ID policy in place (Lord et al., 2010; Parnes, 2008). Among those governments and NGOs that do have such a policy, much empty rhetoric fills the pages. As a result, when disability projects are carried out, they tend to be small, uncoordinated and unsustainable (ibid, p. 12-13). It is clear, therefore, that mainstreaming disability into development cooperation efforts has a long way to go. This is even more surprising given the strong link between ID and poverty (Braithwaite and Mont, 2009). Among children with ID in developing countries, are those from the poorest of the poor households. They are the ones most likely to be shunned by society and even family resulting in poor social networks such as being denied education.

Several studies have been conducted in various cultural contexts to examine the lives of parents who are raising a child with ID, but many are conducted in the western countries. In the United States, Gona et al., (2011) found that families have been as much burdened by the responsibility of caring of a child with ID. As a social institution and system of care, family caregivers play a crucial role in their ill member's healthcare and service utilization (Thomson, Kerr, Glynn \& Linehan, 2014). They form a vital institution in the society as they are the first and, frequently, the last contact of care.

In Africa, the extended family would be available to take care of the children with ID easing the burden on the nuclear family. Hasting (1997) cited in Gona et al., (2011) agreed that extended family support decreased stress among members of the nuclear family. However, with the recent shift to urban areas, the level of support obtained from extended families has changed as families are nowadays much smaller. As evidenced in a study by Hartley et al. (2005), the extended family systems are breaking down in Africa and caregiver's tasks are usually the responsibilities of female caregivers. The problem has also been compounded with the rise of single parent families in Africa, which diminishes the amount of support available to families of CWD (Clark \& Hamplova, 2011). 


\section{International Journal of Social Science and Economic Research}

ISSN: $2455-8834$

Volume:05, Issue:12 "December 2020"

In Kenya, the unpaid care and support provided by families makes a major contribution to the health and social service system, which would be very costly to replace with paid formal service (Kuria \& Ndetei, 2013). However, members in these families do not plan to be caregivers but find themselves in such unavoidable circumstances. This has consequences for their health and well-being, the quality of their relationships and long term financial stability. Such complexities need to be recognized and acknowledged in policy and practice in support of caregivers and their families. Studies on effect of caring for children with intellectual disabilities exist, but most have focused on evaluating of the experiences of the primary caregiver as an individual. Few studies such as Thomson et al. (2014) showcase that caring for a child with ID does not affect the primary caregiver only but also impacts on other members of the family and the functioning of the family as a unit. However, from the studies reviewed so far, none have been conducted within the Kenyan context. Consequently, there is little knowledge regarding the specific challenges encountered by families of children with ID in the country. It is against this backdrop that this study sought to explore in depth, the effects of social cultural implications of caring for children with intellectual disability on family well-being with a specific focus on families of children with ID in Nakuru municipality, Kenya.

\section{Literature Review}

Like many other health problem, ID is often viewed as an individualistic problem that is a product of bad luck, genetic fate, and poor lifestyle (Barnes, 2012). This view is very simplistic. Intellectual disability should be viewed as a social problem because it occurs within a social context: hence, it is shaped and also shapes social environment in which it occurs. Traditional mental health models viewed mental conditions as individual problems resulting in development of response measures that are aimed at helping the individual rather than reform the wider social system (Germov, 2013). Sociology recognizes that human beings are social animals, and products of their environment. Human beings are also influenced by social structures such as cultural traditions and social institutions. Taking a sociological perspective in studying health issues such as intellectual disability encourages scholars to examine how social structures and institutions influence and are influenced by the health issues (Barnes, 2012).

Consequently, scholars are able to explore broader and more comprehensive solutions that go beyond addressing the need of the individual experiencing suffering from these conditions. The sociological perspective recognizes that health is a collective responsibility (Barnes, 2012). Consequently, it focuses on examining the social determinants and consequences of health problems. It goes beyond exploring treatment options and clinical services to exploring social issues such as the patient living and working conditions, health infrastructure, legislation, social services, community action, equity and access issues (Germov, 2013). The sociological 


\section{International Journal of Social Science and Economic Research}

ISSN: $2455-8834$

Volume:05, Issue:12 "December 2020"

perspective assumes that health and illnesses are a social construction that are caused by and have an impact on political, cultural, legal, social, and economic factors. This claim has been supported in various empirical studies.

The challenges experienced by individual with intellectual disability are shared by other people such as family members, teachers, and friends (Ambikile and Outwater 2012). Olsson \& Hwang (2008) suggested that caring for a child with ID can affect the lives of parents and siblings and is often linked with stress, particularly in mothers, as they are the main caregivers. These people also have a significant implication on the quality of life of the child with ID. In addition, social conditions such as availability of reliable and affordable health services, access to special education services, and cultural practices have an impact on the overall well-being of the individual with ID. Therefore, there is a need to analyse intellectual disability from a social perspective. Studies from Uganda reveal that carers of children with disabilities, who are mainly mothers or grandmothers, are subjected to stress in the form of physical ailments, isolation and insufficient time for other household chores (Bwana \& Kyohere, 2001; Hartley et al. 2004). Therefore, this study further sought to establish the conditions faced by the caregivers' and other family members in the study area in comparison with earlier studies.

A major socio-cultural issue that families of children with ID encounter is stigmatization. Park and Park (2014) defined stigma as the tendency to look down upon, disgrace, or exhibit negative emotions towards the person with disability or the family members because of their condition. These authors acknowledged that stigma can be directed to the individual with disability or the entire family. Aldersey, Kavira, Kiasimbua, Lokako, Miaka, and Monte (2018) observed that stigmatization was a major problem among families of children with intellectual disabilities in Kinshasa in the Democratic Republic of Congo. This was a qualitative study that interviewed 20 family members of children with ID. Results showed that stigmatization was mainly manifested through negative stares, refusal to touch the child with ID or family members, and using negative language and names in references to the child with ID or family members. Results also showed that stigmatization left the family members feeling angry, embarrassed, and frustrated. The study by Aldersey et al. (2018) did not however assess how stigmatization affects the well-being of families of children with ID. This study fills this gap by exploring the relationship between stigmatization and well-being of families of children with ID in Nakuru Municipality.

Another major social implication is disrupted family relationships. Families of children with hearing or speech deficits face challenges of a break-down in communication because of inadequate knowledge in the use of signs (Hartley et al. 2004). The breakdown in communication leads to the deterioration in the quality of family relationships. In his longitudinal study, Nind (2008) also found that the presence of children with ID was associated 


\section{International Journal of Social Science and Economic Research}

ISSN: $2455-8834$

Volume:05, Issue:12 "December 2020"

with delinquency, drinking, and employment difficulties among other members of the family. These social problems tend to diminish the quality of relationship within the family of the child with ID. The problems may lead to separation of married couples when one of the partners develops negative coping strategies. In their study, Vahav, Hogoel, and Sara (2015) found that there were many incidents of singlehood among adults with intellectual disability. The study revealed that all participants had a desire to have intimate relationship, but this desire has largely been ignored by society.

Simplican, Leader, Kosciulek, and Leahy (2015) also found high incidents of social isolation of individuals with disability and their families. Payne (2012) also found that there was a strong association between mental health, poverty, and social exclusion. She also found that the relationship between poor mental health, poverty, and social exclusion was a two-way traffic. The issue of isolation was also observed in the study by Ngo, Shin, Nhan, and Yang (2012) that collected data from 70 parents of children with ID in Hue City of Vitenam. Results revealed that parent of children with intellectual disability experience rejection from other members of community. Other parents withdrew from social interaction in order to avoid the negative emotions of being stigmatized for having a child with ID. The works by Simplician et al. (2015) Payne (2012) and Ngo et al. (2012) show that social exclusion is major problem among families of children with disability. The current study also sought to explore whether families taking care of children with ID in Nakuru Municipality also experience social exclusion.

\subsection{Family Systems Theory}

The family systems theory is a theory that tries to explain how families work. This theory views the family as a system that is made up of components and relationship between these components. The theory was developed by Murray Bowen in 1980 using concepts from Ludwig von Bertalanffy's General Systems Theory (Brown, 2008). One of the main concepts that underlie this theory is that the functioning of individual members of the family shapes the functioning of the entire family system. This theory recognizes the interdependence and interaction between individual members of the family, as well as, the wholeness of the family. It suggests that the well-being of each member of the family is dependent and related on the wellbeing of the other members (Haefner, 2014). For instance, if one of the couples remains unemployed because he or she has to take care of the mentally handicapped child, the situation not only affects this couple but also affects the entire family.

Another concept that underlies the family system theory is the interaction between members of the family. Systems theory does not focus on the role of individual members only, but also feedback processes and causal chains that arise from the interaction between family members 
International Journal of Social Science and Economic Research

ISSN: 2455-8834

Volume:05, Issue:12 "December 2020"

(Brown, 2008). It suggests that the functioning of the family system as a whole is not equivalent to the sum of the function of individual members because the interaction between individual members creates casual chain and feedback processes. The theory also introduces the idea of family boundaries and the permeability of these boundaries (Haefner, 2014). It maintains that due to the permeability of these boundaries, the well-being of the family is not affected by the functioning of individual members only, but also by the reciprocal relationship that exist between the family and other systems such as neighbourhood, school, and parents' workplace.

\section{Method}

The current study made use of the descriptive research design, which entailed assessing the existing situation within the study area relating to the study variables without manipulating the variables in any way. This design combined both quantitative and qualitative research methods.

\subsection{Study Area}

The Urban and Cities Act 2011 defines a Municipality as areas whose population is at least 250,000 residents as at the last population and housing census (Republic of Kenya, 2011). Nakuru Municipality had a population of 570,674 in 2019 (Kenya National Bureau of Statistics, 2019); hence, the town satisfies the definition of a municipality. Nakuru town is cosmopolitan comprising of a populace of diverse ethnicity and nationality. According to the Nakuru County Integrated Development Plan 2013- 2017, there are few institutions that cater for the needs of person living with disabilities in Nakuru and the existing institutions do not offer secondary or tertiary educations; thus, students have to go outside the county for further education (County Government of Nakuru, 2013). Another challenge is that there is limited data pertaining to persons living with intellectual disabilities in Nakuru town, which necessitates this current study, which has focused on mental disabilities and how it affects the family well-being. The unit of analysis in this study was the family of children with ID.

\subsection{Population and Sampling procedure}

The population of this study comprised of families of children living with intellectual disability within Nakuru Municipality. Special schools for mentally handicapped located in Nakuru municipality were used as a sampling frame. The schools formed the most appropriate sampling frame given that families of children with ID are a relatively hidden population that are difficult to identify. The schools provided an easy avenue for accessing this population. According to statistics from the Ministry of Education offices in Nakuru County, there are eight special schools for mentally handicapped within Nakuru Municipality, which have a combined total of 503 students (see table 3.1). 
International Journal of Social Science and Economic Research

ISSN: 2455-8834

Volume:05, Issue:12 "December 2020"

Table 1: Schools for Mentally Handicapped Children in Nakuru

\begin{tabular}{lc}
\hline School & Number of Students \\
\hline Menengai Special School & 38 \\
Hill Special School & 180 \\
Our lady Fatima Special School & 15 \\
Our Lady Mercy Special School & 10 \\
Our Lady Victoria Special School & 36 \\
Nakuru North Special School & 19 \\
Muriundu Special School & 25 \\
Pangani Special School & 180 \\
\hline Total & $\mathbf{5 0 3}$ \\
\hline
\end{tabular}

The sample size for the study was determined using the Nassiuma (2000) sample size formula:

$\mathrm{n}=\frac{\mathrm{NC}^{2}}{\mathrm{C}^{2}+(\mathrm{N}-1) \mathrm{e}^{2}}$

Where $\mathrm{n}=$ sample size, $\mathrm{N}=$ target population (503 for this study), $\mathrm{C}=$ coefficient of variation ( $30 \%$ for this study), e= margin of error ( $3 \%$ for this study). Using this formula, the appropriate sample size will be:

$\mathrm{n}=\frac{503 * 0.3^{2}}{0.3^{2}+(503-1) 0.03^{2}}$

$\mathrm{n}=83.6 \approx 84$ families

A sample of 84 families was selected from the families of the 503 students using the proportionate cluster sampling method. This method entailed dividing the population into segments known as clusters and then selecting respondents from each cluster based on the proportion of the clusters' population to the total study population. The eight special schools in Nakuru Municipality were treated as clusters. This sampling method was used because it increased the representativeness of the sample by ensuring that participants are drawn across all schools. 
International Journal of Social Science and Economic Research

ISSN: 2455-8834

Volume:05, Issue:12 "December 2020"

Table 2: Sampling Plan

\begin{tabular}{lcc}
\hline School & Number of Students & Number of Participants \\
\hline Menengai Special School & 38 & 6 \\
Hill Special School & 180 & 30 \\
Our lady Fatima Special School & 15 & 3 \\
Our Lady Mercy Special School & 10 & 2 \\
Our Lady Victoria Special School & 36 & 6 \\
Nakuru North Special School & 19 & 3 \\
Muriundu Special School & 25 & 4 \\
Pangani Special School & 180 & 30 \\
\hline Total & $\mathbf{5 0 3}$ & $\mathbf{8 4}$ \\
\hline
\end{tabular}

The purposive sampling technique was used to select respondent in each school. This method entailed selecting respondents based on the researchers' judgment regarding their ability to provide needed information. According to Olszewski, Shen, and Jiang (2011), definition of inclusion criteria increases objectivity of qualitative studies by minimizing sampling bias. The inclusion criteria, in this study, included: (1) the family of the student must be residing in Nakuru Municipality, (2) the family must have lived with the disabled child for at least five years, and (3) the family must be willing to participate in the study. The researcher worked closely with teachers from the eight schools to identify students whose families meet these criteria.

\subsection{Data Collection Methods}

This study used the interview method to collect data from the head of the 84 households that were selected. The interview guide was semi-structured meaning that it comprised both openended and close-ended questions. It was divided into three sections with the first section exploring the respondents' characteristics, the second section collecting data relating to the wellbeing of the families, and the third section collecting data about the socio-cultural implication of caring for a child with ID.

\subsection{Data Analysis Methods}

Descriptive statistics and the chi-square test were used to assess responses to the closed-ended questions. These questions were coded into the Statistical Packages for Social Sciences (SPSS) version 25 where they were analysed using percentages and frequencies. Descriptive statistics were used to describe the existing state with the families of children with ID in respect to family well-being and socio-cultural implication of taking care of a child with ID. The chi-square test 
International Journal of Social Science and Economic Research

ISSN: 2455-8834

Volume:05, Issue:12 "December 2020"

was used to examine whether there is a significant relationship between family well-being and socio-cultural implications associated with caring for a child with ID.

Thematic content analysis was used to analyse responses to the open-ended questions. This technique focused on identifying frequently occurring themes within the participants' responses and using them to construct patterns (Percy, Koster \& Kostere, 2015). The researcher went through the transcript from each interview in order to identify themes. The focus was on both pre-established and emerging themes. Finally, the researcher combined themes from all of the 84 interviews in order to construct patterns that are important in describing the phenomenon of interests.

\section{Results}

The response rate of the study was $100 \%$ mainly because the questionnaire was administered by the researcher on the spot immediately after the respondents agreed to participate. This reduced the chance of questionnaire getting lost or some questionnaires being returned with many incomplete questions. The sampling technique used gave the researcher freedom to proceed with the selection of the respondents until the desired sample size was reached.

\subsection{Respondents and Family Background Information}

The characteristic of the respondents and families involved in the study were analysed to determine the representativeness of the sample and support the transferability of findings. According to Percy et al. (2015), providing information about the people involved in a study support the application of the study findings to other situation.

Results in Table 3 illustrates that the majority of the respondents $(60.7 \%)$ were female while the remaining $39.3 \%$ were male. This gender distribution can largely be attributed to the fact that the study targeted the primary caregiver in the family to provide information about the experiences of the family. WHO (2011) observed that women, more specifically mothers, bear the largest burden of caring for children with disabilities. This implies that the gender distribution of the respondents follows the general pattern of the gender distribution of caregivers of children with disabilities.

Table 3 Respondents and Family Background Information

\begin{tabular}{llc}
\hline Variable & Categories & Statistics \\
\hline Gender of Respondent & Male & $39.3 \%$ \\
& Female & $60.7 \%$ \\
\cline { 2 - 3 }
\end{tabular}


International Journal of Social Science and Economic Research

ISSN: 2455-8834

Volume:05, Issue:12 "December 2020"

\begin{tabular}{llc}
\hline Age of Respondent & Mean & 41.67 years \\
& Minimum & 24 years \\
& Maximum & 71 years \\
\hline Marital Status of the Respondent & Single & $22.6 \%$ \\
& Married & $57.1 \%$ \\
& Divorced/ Separated & $7.2 \%$ \\
& Widow/ Widower & $13.1 \%$ \\
\hline Respondent's Relationship with the child & Parent & $73.8 \%$ \\
with ID & Sibling & $10.7 \%$ \\
& Uncle/ Aunt & $15.5 \%$ \\
\hline Family Size & Mean & 4.1 members \\
& Minimum & 2 members \\
& Maximum & 9 members \\
\hline Age of the Child with ID & Mean & 13.83 years \\
& Minimum & 4 years \\
& Maximum & 21 years \\
\hline
\end{tabular}

The average age of the respondents was 41.67 years with youngest being 24 years and the oldest being 71 years old. The findings indicate that although the majority of the respondents were in the middle adulthood, the sample was quite diverse in terms of age. In terms of marital status, the majority of the respondents $(57.1 \%)$ were married suggesting that the majority of the families taking care of children with ID in Nakuru Municipality are dual parent families. This structure has an implication on the well-being of the family as dual parents can share the responsibilities involved in taking care of the child with ID as well as taking care of the rest of the family (Allred, 2013). However, about $22.6 \%$ of the respondents were single, $13.1 \%$ were widows or widowers and $7.2 \%$ were divorced or separated. These families are more vulnerable to the stress and burden of taking care of a child with ID.

The majority of the respondents (73.8\%) were parents of the child with ID while $10.7 \%$ were siblings and $15.5 \%$ of were uncle and aunt. Chambers and Chambers (2015) observed that the relationship between the caregivers and the child with ID determines the experiences and wellbeing of the family. Where there exist a strong and close connection between the child with ID and the caregiving family, family members are often willing to accommodate the demands of caring for the child and thus the impact of caregiving on the social and psychological well-being of the family members is often minimized. About $10.7 \%$ of the respondents reported that they were siblings of the child with ID while $15.5 \%$ were either uncles or aunties to the child with ID. 


\section{International Journal of Social Science and Economic Research}

ISSN: $2455-8834$

Volume:05, Issue:12 "December 2020"

The sampled families had an average of 4.1 members. This family size is equivalent to the national average that stood at 3.9 members per family in the 2019 National Population and Housing Census (Kenyan National Bureau of Statistics, 2019). A small family size may have a positive effect on family well-being as it may reduce the economic demands of the family thus enabling the family to direct some of its resources towards the treatment of the child with ID. A small family size also reduces the caregiving burden of parents as they do not have to take care of many children alongside the child with ID.

The average age of the child with ID was 13.83 years with the youngest being 4 years and the eldest being 21 years. The study presumed that the age of the child has an influence on family well-being as it determines the amount of care that the child needs. A younger child needs more care around the clock as compared to an older child. Another factor that determines that amount of care that a child need is the severity of disability. The severity of the child disability was also interrogated by examining the function that the child is capable of fulfilling. The findings are summarised in Table 4.

Table 4: Functioning of the Child with Disability

\begin{tabular}{lcc}
\hline Function & No (\%) & Yes (\%) \\
\hline Is the child able to take care of his/ her personal hygiene? & 44.1 & 55.9 \\
Is she/he able to communicate? & 6 & 94.0 \\
Is she/he able to travel independently? & 88.1 & 11.9 \\
\hline
\end{tabular}

Results in Table 4 show that the majority of the children with ID (55.9\%) in the sampled families could take care of their personal hygiene such as bathing, brushing their teeth, getting dressed, and going to the toilet (Chambers \& Chambers, 2015). Providing assistance on personal hygiene is one of the daunting tasks involved in caring for a child with ID. If a child is able to perform most of these basic personal care tasks, the burden of caregiving is reduced substantially. The majority of the children with ID $(94.0 \%)$ could communicate by having conversations and using the phone. Ability to communicate also reduces the burden of caregiving substantially as it enables these children to do some things on their own or even to assist with some chores in the house such as going to the shop. The majority of children with ID (88.1\%) could however not travel independently. This implies that most of the children have to be accompanied when going to school or hospital, which increases the burden of caregiving.

\subsection{Family Well-Being}




\section{International Journal of Social Science and Economic Research}

ISSN: $2455-8834$

Volume:05, Issue:12 "December 2020"

The dependent variable of the study was family well-being. To assess this issue, respondents were presented with a set of ten questions assessing various aspects of family well-being, to which they were expected to respond with a "No" or "Yes" answer. Table 5 presents the number and percentage of respondents who gave a positive response (Yes) indicating that that particular element of family well-being was present in his or her family.

Results in Table 5 illustrates that $85.7 \%$ of the respondents affirmed that their family member enjoy spending time together. This question was intended to assess family relationship, which is an important indicator of family well-being (Noor, Gandhi, Ishak, \& Wok, 2012). Results suggest that the majority of families taking care of children with ID have good family relationships. The finding also implies that taking care of the child with ID has not taken a toll on the relationship between family members. This position is further reinforced by responses to question 6 where $83.3 \%$ of respondents reported feeling safe and comfortable at home, responses to question 7 where $89.3 \%$ of respondents said that their family members support each other to accomplish goal, as well as responses to question 8 where $84.5 \%$ of the respondent indicated that they often solve issues together as a family.

Table 5: Respondents Views on different Aspects of Family Well-Being

\begin{tabular}{lll}
\hline S/N & Question & Yes \\
& & N (\%) \\
\hline 1 & Do your family members enjoy spending time together & $72(85.7)$ \\
2 & Do your family members have friends who provide support & $50(59.5)$ \\
3 & Do your family members have time to pursue their own interest & $57(67.9)$ \\
4 & Do all family members get medical care when needed & $29(34.5)$ \\
5 & Do you find it easy to take care of family expenses & $2(2.4)$ \\
6 & Do you feel safe and comfortable at home & $70(83.3)$ \\
7 & Do your family members support each other to accomplish goals & $75(89.3)$ \\
8 & Do you often solve issues together as a family & $71(84.5)$ \\
9 & Do all family members get adequate and balanced diet & $33(39.3)$ \\
10 & Do family members have adequate access to transportation services & $38(45.2)$ \\
\hline
\end{tabular}

Table 5 further shows that $59.5 \%$ of the respondents gave an affirmative response to question 2 indicating that their family members have friends who provide support. This question was geared towards assessing the social relations and community connectedness of individuals belonging to families caring for children with ID. It was founded on the premise that families taking care of children with disabilities are subjected to social stigma, which hinders them from developing good relationship with other members of their communities. This study's findings suggest that 


\section{International Journal of Social Science and Economic Research}

ISSN: $2455-8834$

Volume:05, Issue:12 "December 2020"

this is not the case with most families taking care of children with ID in Nakuru Municipality. The findings show that family members in most of these families have been able to overcome stigma and develop relations with other community members. However, a sizeable proportion of the respondents (40.5) gave a negative response suggesting that their family members are not able to develop good social relations and connection with other people in their communities.

Similarly, $67.9 \%$ of the respondents gave an assenting response to question 3 indicating that members in their family get time to pursue own interests. This question assessed the element of achievement in life, which was identified by Noor et al. (2012) as another indicator of family well-being. It was based on the assumption that taking care of a child with disability may prevent family members from pursuing their own interests and consequently prevent them from achieving their life goals. Current finding confirm that has not been the case among families taking care of children with ID in Nakuru Municipality. Available data shows that individuals in more than two-thirds of the sampled families are able to pursue own interests which increases their chances of achieving their life goals.

In response to question 3, less than half of the respondents $(34.5 \%)$ confirmed that all their family members get medical care when needed. This question sought to assess the health of members of families taking care of children with ID. It was grounded on the notion that the burden of taking care of a child with ID would hamper the families' ability to provide care to its members. This study's findings confirm this notion as the majority of the respondents indicated that their family members do not get medical care when needed. Limited access to medical care has a negative implication on the heath of the family members. The issue of health is also captured in question 9 that assessed access to adequate and balanced diet by members of families of children with ID. Similarly, less than half of the respondents (39.3\%) said that they are able to get adequate and balanced diet.

In addition, only $2.4 \%$ of the respondents gave a "Yes" response to question 5 , which probed the families' ability to cater for household expenses. This finding suggests that the majority of families taking care of children with ID in Nakuru Municipality are struggling to meet their basic needs. The finding is reinforced by responses to question 10 where less than half of the respondents $(45.2 \%)$ said that members in the families have adequate access to transport services. This finding shows that transportation is one of the basic needs that most of the families of children in ID are struggling to meet. Finding suggests that most of these families are also struggling to meet other basic needs and this situation has a negative impact on their well-being.

In general findings in Table 5 indicate that the social well-being of most families taking care of children with ID in Nakuru municipality has been affected by their situation. Most of these 


\section{International Journal of Social Science and Economic Research}

ISSN: $2455-8834$

Volume:05, Issue:12 "December 2020"

families have managed to maintain good relationship within the family and with community members and have strong community ties. However, their economic well-being has been affected marked by difficulties in accessing health care, quality nutrition, and essential services such as transportation. This finding is further support by the qualitative data that was obtained from the responses to an open-ended follow-up question that prompted participants to share their experiences on how life in their families has been like since they started taking care of the child with ID. In response to this question, the largest position of the respondents $72.6 \%$ raised issues that point to financial difficulties. Responses from some of the respondents were as follows:

"Life has been a bit challenging. My child requires expensive medication and complex treatment procedures, which has really affected us financially. When money is not available, the child goes without medication making his condition worse." (Respondent 13, female, 36 years old)

"Our life has drastically changed. The child requires a lot of attention since she cannot do most of the things that children do. We have been unable to get a house help who can withstand the demand of taking care of the child. Many stay for a few weeks and leave. Eventually, my wife had to leave her job and take care of the child. This has really hit us hard, financially." (Respondent 62, male, 44 years old)

From the above narration, it is clear that most families of children with ID are struggling to cope with financial demands of taking care of a child with ID. These families have had to accommodate additional expenses associated with providing treatment and care to the child with ID. In some families, one parent has been forced to stay at home and take care of the child leaving the breadwinning responsibility to the other parent. To facilitate further analysis on how socio-cultural factors, economic cost, and coping strategies influence the well-being of families of children with ID, data for all the 10 items in Table 4.3 was aggregate to obtain a single family well-being score. The aggregation was done by coding all "No" responses as 0 and all "Yes" responses as 1 resulting in an aggregate well-being scale that ranged from 0 (for respondents who gave a "No" response to all the ten questions) to 10 (from respondents who gave a "Yes" response to all the ten questions). A higher score thus signifies greater family well-being. Since the study intended to use the chi-square test to assess the relationship between the independent variable and family well-being, the aggregate data on family well-being was converted into category data by classifying the families that had score of 5 and below as having low well-being and those that had scores of 6 and above as having high well-being. The distribution of the 84 families involved in the study across the two categories of well-being is summarized in Figure 1. 


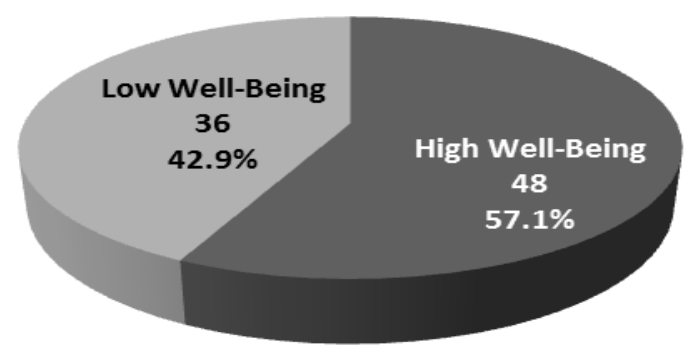

Figure 1: Distribution of Families according to their State of Well-being

Figure 1 illustrates that the majority of the families $(57.1 \%)$ had high well-being. This means that these families had an aggregate well-being score of 6 or above. It implies that from the perspective of the respondents, the families exhibit most of the ten indicators of well-being measured in Table 4.3. Figure 4.1 however reveals that more than a third (42.9\%) of the families are in a low state of well-being as measured in terms of economic well-being, family relationship, and social relations and community connectedness.

\subsection{Influence of Socio-Cultural Implication on Family Well-being}

The first objective of the study was to assess the influence of socio-cultural implications of taking care of a child with ID on family well-being. The study observed that families taking care of children with ID encounter certain socio-cultural consequences. The study focused on three main socio-cultural issues namely: stigmatization from friends, stigmatization from the extended family, and disrupted family relationship.

\subsubsection{Stigmatization by Friends and Community Members on Family Well-Being}

To assess the issue of social stigma, respondents were asked to indicate whether any of their family members has experienced negative judgment by friends for having a child with ID in the family. This was a structured question that prompted participants to respondent with a "Yes" or "No" answer. The responses are summarized in Figure 2. 


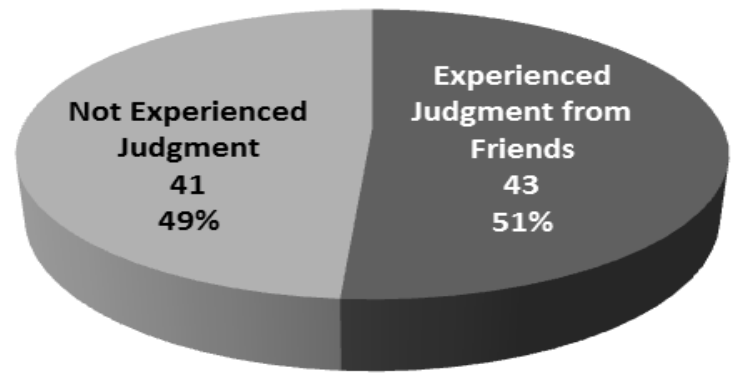

Figure 2: Distribution of Respondents based on Judgment by Friends

Figure 2 illustrates that more than half of the respondents (51\%) have experienced negative judgment from friends because of having a child with ID in their family. The finding indicates that social stigma is a big reality for most families living with children with ID. To further assess this issue, respondents who reported that a member of their family had experience negative judgment from friends were asked to share some of the negative encounters that they have had with friends. From the responses, it emerged that most of stigma encountered by the family emanate from friends and community members beliefs that associated ID with witchcraft or sins. Some of the respondents recounted as follows:

"I try to avoid some of my friend and neighbour because they keep telling me to pray. They believe that having a child with this condition is the work of the devil." (Respondent 6, female, 29 years old)

"There is this one time when I was in Matatu with my child. It occurred that my child touched another child whose mom was seated next to us. The mother of this other child quickly shoved off the hand of my girl. This really hurt me. It is like she thought that my child could infect her child with the intellectual disability." (Respondent 29, male, 45 years old)

"My other children told me that they experience ridicule at school with some of their peers saying that the family has been bewitched." (Respondent 74, female, 37 years old)

These accounts confirm that stigmatization by friends is a reality that individuals in most families of children in ID encounter. It emerges some families have to deal with having their children ridiculed for having a sibling who has an intellectual disability. The influence of 


\section{International Journal of Social Science and Economic Research}

ISSN: $2455-8834$

Volume:05, Issue:12 "December 2020"

stigmatization by friends on family well-being was assessed by cross-tabulating the data on stigmatization by friend with data on family well-being.

Results in Table 6 shows in the category of families whose members have not experienced negative judgment from friends, the majority of the families (65.9\%) had high well-being. Conversely, in the category of families whose members have experienced negative judgment from friends, the majority of the families (51.2\%) had low family well-being. This result suggests that there is some negative relationship between stigmatization by friends and family well-being as most families whose members had encounter stigma from friends had low wellbeing score.

Table 6: Cross-Tabulation of Stigmatization by Friend with Family Well-Being Data

\begin{tabular}{|l|l|l|l|l|}
\hline \multicolumn{2}{|c|}{} & \multicolumn{2}{|c|}{ Family Well-Being Categories } & \\
\cline { 3 - 5 } \multicolumn{2}{|c|}{} & Low Well-Being & High-Well-being & Total \\
\hline $\begin{array}{l}\text { Stigmatization } \\
\text { by Friends } \\
\text { Categories }\end{array}$ & $\begin{array}{l}\text { Not Experienced } \\
\text { Judgement }\end{array}$ & $14(34.1 \%)$ & $27(65.9 \%)$ & $41(100 \%)$ \\
\cline { 2 - 5 } & $\begin{array}{l}\text { Experienced } \\
\text { Judgement }\end{array}$ & $22(51.2 \%)$ & $21(48.8 \%)$ & $43(100 \%)$ \\
\hline Total & $\mathbf{3 6 ( 4 2 . 9 \% )}$ & $\mathbf{4 8 ( 5 7 . 1 \% )}$ & $\mathbf{8 4}(\mathbf{1 0 0 \%})$ \\
\hline Chi-square $\mathrm{X}^{2}=1.285$, d.f. $=1$, sig. $=0.074$ & & \\
\hline
\end{tabular}

However, the chi-square statistics show that the relationship between stigmatization by friends and family well-being is not statistically significant $\left(\mathrm{X}^{2}=1.285, \mathrm{p}>.05\right)$. This implies that stigmatization by friends does not have a noteworthy impact on the well-being of families living with a child with ID. The most probable explanation is that families of children with ID do not pay too much attention to the reaction that they receive from friends and family. It is also probable that most families that are subjected to stigma by friends and community members have found mechanism for overcoming this source of stigma.

\subsubsection{Stigmatization by the Extended Family and Nuclear Family Well-Being}

Social stigmatization may come from different quotas. Previous analysis focused on stigmatization by friends. The study also sought to find out how stigmatization by members of the extended families affects the well-being of the nuclear family taking care of a child with ID. To assess this issue, respondents were asked to indicate whether any member of their nuclear 
International Journal of Social Science and Economic Research

ISSN: $2455-8834$

Volume:05, Issue:12 "December 2020"

families has experienced negative judgment from the extended family. This was a structured question that needed a "Yes" or "No" answer. Results are summarized in Figure 3.

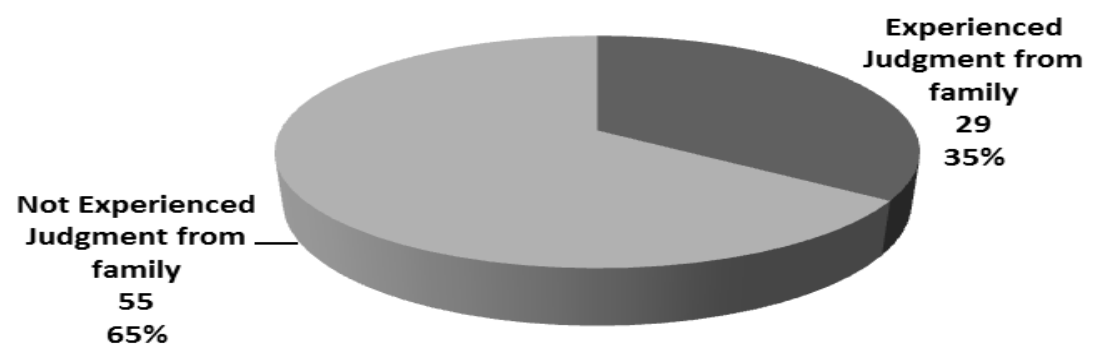

Figure 3: Distribution of Respondents based on Negative Judgment by Family

Figure 3 shows that the proportion of families that has been subjected to stigmatization by their extended families (35\%) is smaller than the proportion of families subjected to stigma by friends (51\%). This results implies that social stigma experienced by families of children with ID largely emanate from friends and community members rather than from the extended family. This may be attributed to the fact that interaction with friends and community members is more frequent than interaction with members of extended families for individual living in an urban set-up. To further interrogate the nature of stigmatization from extended family, respondents who acknowledge that their family had experienced this kind of stigma were asked to share some of the negative prejudices that they have encountered from their extended family. The most dominant theme that emerged from their responses was that of avoidance. Sixteen respondents (19\%) gave accounts that suggested their family had been abandoned by the extended family because of having the child with ID. Some of the accounts given were as follows.

"Many of our extended family members don't come to visit us or offer any kind of support. They also don't involve us in their functions such as weddings. It is like they try to avoid us." (Respondent 11, male, 35 years old)

"Our extended family does not want to associate with us. They believe that having this sick child is a punishment for doing bad things or a result of witchcraft. Others believe that my child would infect their children with the disease and choose to stay away." (Respondent 39, female, 43 years old)

"We do not have a good relationship with our extended family. My mother inlaw told me that they have never had this kind of sickness in their family. It was like saying that this is not their child." (Respondent 72, female, 34 years old) 
International Journal of Social Science and Economic Research

ISSN: 2455-8834

Volume:05, Issue:12 "December 2020"

These accounts highlight that avoidance from the extended family is a common challenge among families taking care of a child with ID. The accounts also indicate that the stigmatization by family members is largely founded on misconception regarding the causes of ID. It is evident that some families have been abandoned because their kin believe that the disease is caused by witchcraft or sin. The belief that ID is contagious has also contributed to the isolation of families of children with ID by their kin. The relationship between stigmatization by extended family and well-being of the nuclear family of the child with ID was tested using cross-tabulation with chisquare. Table 7 presents the results.

Table 7: Cross-Tabulation of Stigmatization by Extended Family with Family Well-Being

\begin{tabular}{|l|l|l|l|l|}
\hline \multirow{2}{*}{\multicolumn{2}{|c|}{}} & \multicolumn{2}{|c|}{ Family Well-Being Categories } & \\
\cline { 3 - 5 } & Low Well-Being & HighWell-being & Total \\
\hline $\begin{array}{l}\text { Stigmatization } \\
\text { by Extended } \\
\text { Family } \\
\text { Categories }\end{array}$ & $\begin{array}{l}\text { Not Experienced } \\
\text { Judgement }\end{array}$ & $15(27.3 \%)$ & $40(77.7 \%)$ & $55(100 \%)$ \\
\cline { 2 - 5 } & $\begin{array}{l}\text { Experienced } \\
\text { Judgement }\end{array}$ & $21(72.4 \%)$ & $8(27.6 \%)$ & $29(100 \%)$ \\
\hline Total & $\mathbf{3 6 ( 4 2 . 9 \% )}$ & $\mathbf{4 8}(\mathbf{5 7 . 1 \%})$ & $\mathbf{8 4}(\mathbf{1 0 0 \%})$ \\
\hline Chi-square $\mathrm{X}^{2}=6.845$, d.f. $=1$, sig. $=.000$ & & \\
\hline
\end{tabular}

Table 7 reveals that in the category of families that have not experienced judgment from the extended family, the majority of the families $(77.7 \%)$ have high well-being. In contrast, the majority of the families $(72.4 \%)$ in the category that experienced negative judgment from the extended family have low family well-being. These findings imply that stigmatization by the extended family has a negative influence on the well-being of the nuclear family taking care of a child with ID. The chi-square test shows that this relationship is statistically significant at the 0.01 significance level $\left(\mathrm{X}^{2}=6.845, \mathrm{p}<.01\right)$. These findings imply that stigmatization that comes from the extended family has a substantial influence of the well-being of the nuclear family of the child with ID. They suggest that support and understanding from the extended family is more important to the family of the child with ID when compared to the support and understanding that they receive from community members and friends.

\subsubsection{Disrupted Family Relationship and Family Well-Being}

The final social-cultural factor that was examined was disrupted family relationship. The study sought to find out the extent to which taking care of a child with ID disrupts the relationship between members of the nuclear family and how this disruption affects the well-being of the 
family. To assess this issue, respondents were asked to indicate whether taking care of the child with ID affects relationships between family members using a simple "Yes" or "No" answer. Figure 4.4 presents their responses.

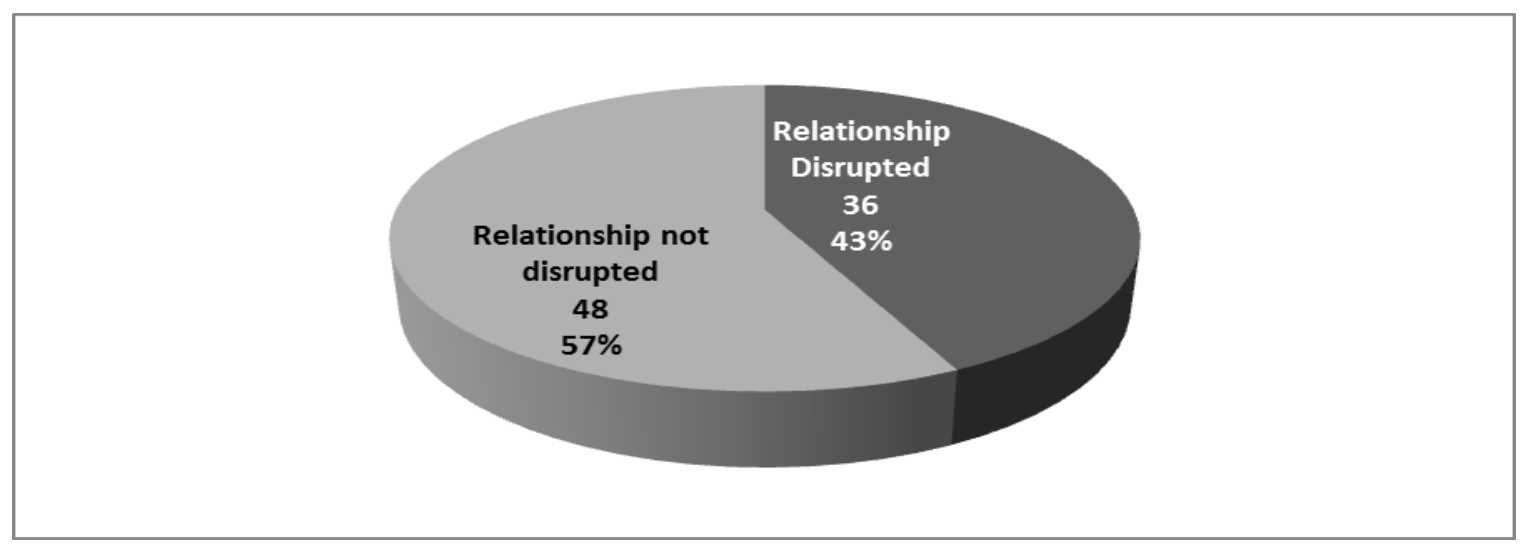

Figure 4: Distribution of Families based on Family Disruption

Results in Figure 4 reveal that relationships in the majority of the families (57\%) have not been disrupted by the presence of the child with ID. This finding implies that most of the families are cohesive, harmonious, and have good internal relationships. They suggest that members of these families have learnt to cope with the demands and responsibilities of taking care of the child with ID. It is also probable that the presence of the child with ID and the responsibilities involved may have served as unifying factor for the families. However, a notable proportion of the families (43\%) have their relationship disrupted by the presence of the child with ID.

To gain in-depth understanding of the relationship challenges, respondents in this category (families with disrupted relationships) were asked to share on how the relationship between family members has been affected in an open-ended question. The response revealed that the presence of the child with ID affected different types of relationships with the families including relationship between parents and the child with ID, relationship between the parents themselves, relationship between the parents and other children, relationship between other children and the child with ID, and the relationship between the other children themselves. Some respondents gave the following narration:

"My relationship with my husband has really changed since this child came into the picture. My husband thinks that I spend too much time with the child and I have ignored him and the other child. I also feel like he hates the child for taking the families through a lot of trouble.' (Respondents 22, female, 39 years old) 


\section{International Journal of Social Science and Economic Research}

ISSN: $2455-8834$

Volume:05, Issue:12 "December 2020"

"Taking care of this child is very overwhelming. I often feel guilty that I have neglected the other children because of this one. The other children are also resentful towards this child because they feel like he has the attention of their parents away from them." (Respondent 58, female, 43 years old)

"My husband left me after I got this child. He ran away from the huge responsibilities involved in taking care of the child. I have been the father and mother to this child for the last 11 years." (Respondent 75, female, 41 years old)

These accounts showcase how the presence of the child with ID has affected the relationships in some families. In the last account, the responsibility of taking care of the child with ID led to the break-up of the marriage. From this account, it becomes apparent that not all parents are willing to tolerate the emotional, physical, financial, and time demands associated with taking care of a child with ID. Some parents are unable to withstand this pressure leading to dissolution of marriages. Dissolution of marriage can also arise when one partner feels that he or she is bearing more than his or her fair share of responsibilities. Culture also plays a role in marriage breakup where spouses share different beliefs regarding how to treat a child with ID. Some respondents reported that they always quarrel with their children regarding how to share the responsibilities of taking care of the child with ID. This implies that taking care of a child with ID does not affect marital relationships only but also impact the relationship between parents and children. Others recount how animosity has developed between the children because of disagreement over responsibilities of taking care of the child with ID and other household chores. The influence of disrupted family relationship on family well-being was tested using the cross-tabulation with chisquare method. Results are summarized in Table 8.

Table 8: Cross-Tabulation of Disrupted Relationship with Family Well-Being Data

\begin{tabular}{|l|l|l|l|l|}
\hline \multirow{2}{*}{\multicolumn{2}{|c|}{}} & \multicolumn{2}{|c|}{ Family Well-Being Categories } & \\
\cline { 3 - 5 } & Low Well-Being & High Well-being & Total \\
\hline $\begin{array}{l}\text { Relationship } \\
\text { Disruption } \\
\text { Categories }\end{array}$ & $\begin{array}{l}\text { Relationship } \\
\text { Disrupted }\end{array}$ & $19(52.7 \%)$ & $17(47.3 \%)$ & $36(100 \%)$ \\
\cline { 2 - 5 } & $\begin{array}{l}\text { Relationship not } \\
\text { Disrupted }\end{array}$ & $17(35.4 \%)$ & $31(64.6 \%)$ & $48(100 \%)$ \\
\hline Total & $\mathbf{3 6 ( 4 2 . 9 \% )}$ & $\mathbf{4 8 ( 5 7 . 1 \% )}$ & $\mathbf{8 4}(\mathbf{1 0 0 \%})$ \\
\hline Chi-square $\mathrm{X}^{2}=3.214$, d.f. $=1$, sig. $=0.031$ & & \\
\hline
\end{tabular}




\section{International Journal of Social Science and Economic Research}

ISSN: $2455-8834$

Volume:05, Issue:12 "December 2020"

Table 8 illustrates that in the category of families with relationship disruption, the majority of the families $(52.7 \%)$ have low family well-being. On the other hand, the majority of the families $(64.6 \%)$ in the category of families that have not experience relationship disruption have high well-being. These findings indicate that disruption of family relationship has a negative influence on the well-being of families taking care of a child with ID. The chi-square test shows that the relationship between relationship disruption and family well-being is statistically significant at the 0.05 level of significance $\left(\mathrm{X}^{2}=3.214, \mathrm{p}<.05\right)$. These findings imply that families whose relationship and functioning are unable to withstand the strains of taking care of a child with ID tend to experience poor standards of living. Disrupted relationship may affect family well-being in different ways including increasing conflicts within the family, reducing the level of marital satisfaction, creating stress and anxiety, and reducing family income when one partner walks away.

\section{Discussion and Conclusion}

This study purposed to establish the effects of social-cultural implications of caring for children with ID on well-being of families in Nakuru Municipality. Findings indicate that the majority of the families of children with ID in the study area have high state of well-being as measured in terms of access to basic needs, family relationships, relationship with other community members, and life achievement. However, more than $40 \%$ of the families are struggling in realizing these elements of well-being. These findings are consistent with the study by McConnell and Savage (2015), which observed that caring for a child with ID increases the risk of psychological, physical, and financial distress among families leading to family dysfunction.

Results also show that the well-being of the families of children with ID is negatively and significantly associated with stigmatization by the extended family. However, stigmatization by friend and community members did not have a significant effect on family well-being. Qualitative findings suggested that stigmatization was as result of the misconception held by people regarding the cause of the disease and how it spreads. Findings also revealed that stigmatization is not just directed to the child with ID but also the family members particularly the parents who are often blamed for the child's condition. This finding is also consistent with the study by Aldersey et al. (2018), who found female parents in Congo were subject to stigmatization by the community for siring children with intellectual disability. The study discovered that these mothers were viewed as inadequate parents who did not get proper prenatal care leading to the deformity in the child.

Aldersey et al. (2018) also observed that stigmatization of children with ID and their family members created negative emotions such as anger and distress. These emotions could explain the 


\section{International Journal of Social Science and Economic Research}

ISSN: $2455-8834$

Volume:05, Issue:12 "December 2020"

mechanism through which stigmatization leads to low state of well-being among families of children with ID. Park and Park (2014) also argued that stigmatization tend to discourage family members from seeking help from healthcare professional, government, and other agencies to avoid exposing their child's condition. As a result, families of children with ID do not get the required assistance. Ngo et al. (2012) also observed that stigmatization of parents of children with ID in Vietnam led to withdrawal from social interaction by some parents leading to social isolation. Current study also found that withdraw from social interaction was among the emotion focused strategies adopted by members of some families of children with ID in Nakuru Municipality.

The study also found that the well-being of families of children with disability was significantly and negatively influenced by disruption in the relationship between family members. Result should that disruption in family relationship was a social problem that affected more than $40 \%$ of the families of children with ID in the study area. Qualitative data further revealed that the responsibilities and challenges of taking care of a child with ID have affected different familial relationship including husband-wife, parent-children, and children-children relationships. These findings are consistent with the study by Hartley et al. (2004) who found that difficulties in communication that characterized most ID hinder the development of fulfilling relationship between the child with ID and other members of the family. Findings also congruent with Nind (2008), who also observed that the challenged involved in taking care of the child with ID may elicit negative coping strategies such as alcohol and substance abuse leading to disrupted family relationship. Current findings revealed that some families have experienced marital break-up due to the strain of caring for the child with ID.

Based on the findings, the study concludes that the well-being of families of children with ID is negatively influenced by stigmatization by the extended family and disruption of relationship within the families of the child with ID. To improve the well-being of these families there is a need for policy and practice interventions for addressing these two socio-cultural issues. In particular, intervention should be directed towards addressing misconception regarding the cause of intellectual disability as results showed that many families are stigmatized because most people associate ID with witchcraft and other spiritual issues. There is also a misconception regarding the pathophysiology of the condition with some people thinking that the condition can be transmitted leading to isolation of the child with ID and their families. Other people believe that the condition occur as a result of mothers' negligence during pregnancy leading to stigmatization of mothers.

The study recommends that policy-makers particularly at the Ministry of Health need to organize nation-wide sensitization campaigns aimed at eradicating negative beliefs regarding intellectual 


\section{International Journal of Social Science and Economic Research}

ISSN: $2455-8834$

Volume:05, Issue:12 "December 2020"

disability and educating Kenyans about the negative effects of stigmatizing persons with ID and their families. The study has established that stigmatization by members of the extent families is one of the effects of taking care of a child with ID that has a significant implication of the wellbeing of these children's families. Mass media would be the most effective channel for carrying out the nationwide campaigns.

The Ministry of Health should also work with their counterparts in the Ministry of Education to develop awareness programmes that seek to sensitize pupils particularly in lower primary grades about intellectual disability and the need to embrace children suffering from this condition. Awareness in schools can also be raised through creative strategies such including awareness message in content for regular subjects such as passages meant to teach language skills to children or in songs and games from pre-primary school children. Policy makers at the County Government can also run local sensitization campaigns through local radio stations and social media.

Practitioners in the mental health specialty such as social workers should also provide psychological counselling to members of families of children with ID to assist them deal with the negative effect of stigma on their well-being. Family counselling should be included as one of the services that is covered by NHIF as part of the treatment of intellectual disability. Counselling will also help family members to overcome the problem of disrupted family relationships, which has been found to have a negative influence on family well-being. It may also help the families to adopt positive problem-focused strategies that have also been linked to high state of well-being.

This study was confined to families of children with ID in Nakuru Municipality. To support the generalization of these findings, the study should be replicated in other areas. In particular, future studies should examine how caring for children with ID influence the well-being of families in rural areas. Future studies should examine a different set of factors such as family income, family structure, parent education level, parent age, and family size. The present study was able to establish the existence of a statistically significant link between family expenditure in providing care of a child with ID and family well-being but did not arrive at a precise conclusion regarding the direction of this relationship. Future studies should examine the direction of this relationship by controlling factors such as family income.

\section{References}

Aldersey, H., Kavira, S., Kiasumbua, J., Lokako, W., Miaka, P., \& Monte, L. (2018). Stigma experienced by families with members with intellectual disabilities in Kinshasa, 


\section{International Journal of Social Science and Economic Research}

ISSN: $2455-8834$

Volume:05, Issue:12 "December 2020"

Democratic Republic of the Congo. Journal of Mental Health and Psychosocial Support in Conflict Affected Areas, 16(2), 119- 128.

Allred, D. (2013). Caregiver burden and sibling relationships in families raising children with disabilities (Unpublished thesis). Brigham Young University, USA.

Barnes, C. (2012). The social model of disability: Valuable or irrelevant? Journal of Disability Studies, 3 (2), 12- 29.

Brown, J. (2008). A discussion of common challenges and confusion about the usefulness of Murray Bowen's Family Systems approach. Journal of the Counsellors and Psychotherapists Association, 3 (1), 11- 17.

Chambers, H., \& Chambers, J. (2015). Effect of caregiving on the families of children and adults with disabilities. Physical Medicine Rehabilitation Clinics of North America, 26(2015), $1-19$.

Clark, S., \& Hamplova, D. (2011). Single motherhood in sub-Saharan Africa: A life course perspective. Journal of Family Issues, 28 (5), 24- 29.

Germov, J. (2013). Imaging health problems as social issues. Oxford University Press. Retrieved from http://lib.oup.com.au/he/health/samples/germov5e_secondopinion_sample.pdf

Haefner, J. (2014). An application of Bowen Family System Theory. Issues in Mental Health Nursing, 35 (11), 135- 141.

Kenya National Bureau of Statistics (2019). Kenya Population and Housing Census Report. Nairobi: Government Printer.

Lakhan, R., Ekundayo, O., \& Shahbazi, M. (2015). An estimation of the prevalence of intellectual disabilities and its association with age in rural and urban populations in India. Journal of Neurosciences in Rural Practice, 6(4), 523- 528.

McConnell, D., \& Savage, A. (2015). Stress and resilience among families caring for children with intellectual disability: Expanding the research agenda. Current Developmental Disorders Reports, 2(1), 100-109.

Ngo, H., Shin, J., Nhan, N., \& Yang, L. (2012). Stigma and restriction on the social life of families of children with intellectual disabilities in Vietnam. Singapore Medical Journal, 53(7), 451- 457. 
International Journal of Social Science and Economic Research

ISSN: 2455-8834

Volume:05, Issue:12 "December 2020"

Nind, M. (2008). Conducting qualitative research with people with learning, communication, and other disabilities: Methodological challenges. Economic and Social Research, 4 (5), 4449.

Noor, N., Gandhi, A., Ishak, I., \& Wok, S. (2012). Development of indicators for family wellbeing in Malaysia. Social Indicators Research, 109(3). DOI 10.1007/s11205-012-0219-1.

Olsson, B., \& Hwang, P. (2008). Socioeconomic and psychological variables as risk and protective factors for parental well-being in families of children with intellectual disabilities. Journal of Intellectual Disability Research, 52 (12), 1102- 1113

Park, S., \& Park, K. (2014). Family stigma: A concept analysis. Asian Nursing Research, 8(3), 165- 171.

Payne, S. (2012). Mental health, poverty, and social exclusion. Economic and Social Research, 9 (1), 131- 137.

Percy, W. H., Koster, K., \& Kostere, S. (2015). Generic qualitative research in psychology. The Qualitative Report, 20(2), 76-85.

Republic of Kenya (2011). The Urban and Cities Act No. 13 of 2011. Nairobi, NB: Government Printer.

Simplican, S., Leader, G., Kosciulek, J., \& Leahy, M. (2015). Social inclusion of people with intellectual and developmental disabilities. Research in Developmental Disabilities, 38 (1), 18- 29.

Thomson, R., Kerr, M., Glynn M., \& Linehan, C. (2014). Caring for a family member with intellectual disability and epilepsy: Practical, social and emotional perspectives. Seizure, 23(10), 856- 863. https://doi.org/10.1016/j.seizure.2014.07.005.

Vahav, H., Hogoel, H., \& Sara, F. (2015). Singlehood among adults with intellectual disability: Psychological and sociological perspective. iMedPub Journals, 1 (2), 603- 625.

Yokota, R., Berger, N., Nusselder, W., Robine, J., Tafforeau, J., Deboosere J., \& Oyen, H., (2015). Contribution of chronic diseases to the disability burden in a population 15 years and older, Belgium, 1997- 2008. BMC Public Health, 15, 229. https://doi.org/10.1186/s12889-015-1574-Z. 
International Journal of Social Science and Economic Research

ISSN: 2455-8834

Volume:05, Issue:12 "December 2020"

Zablotsky, B., Black, L., \& Blumberg, S. (2017). Estimated prevalence of children with diagnosed developmental disabilities in the United States, 2014- 2016. National Center for Health Statistics Data Brief No. 291. Retrieved $3^{\text {rd }}$ March 2019 from https://www.cdc.gov/nchs/data/databriefs/db291.pdf. 